The distribution of responses during the interreinforcement interval was also a function of the ratio of the initial-to-terminal segment duration. This result may be explained by the fact that the different ratios provide differential reinforcement for high rates at different points in the interreinforcement interval. For instance, a tand $24 \mathrm{sec} 96 \mathrm{sec}$ schedule required high rates early in the interreinforcement interval if the $S$ were to maximize the frequency of reinforcement. Even though response rate increased near the end of the interreinforcement interval, the relatively high rates early in the interval would produce a relatively flat response distribution. A tand $96 \mathrm{sec} 24 \mathrm{sec}$ schedule, on the other hand, would provide no differential reinforcement for responding early in the interreinforcement interval. Ss could therefore be expected to show the steeply curved response distribution characteristically observed when a fixed-interval schedule is used.

\section{REFERENCES}

FERSTER, C. B., \& SKINNER, B. F. Schedules of reinforcement. $\mathrm{New}$ York Appleton-Century-Crofts, 1957

FINDLEY, J. D. An experimental outline for building and exploring multi-operant behavio repertoires. Journal of the Experimental Analy sis of Behavior, 1962, 5, 113-166.

KELLEHER, R. T. Chaining and conditioned reinforcement. In W. K. Honig (Ed.), Operant behavior-Areas of research and application. New York: Appleton-Century-Crofts, 1966. P. 160.

KELLEHER, R. T., \& FRY, W. F. Stimulus functions in chained fixed-interval schedules. Journal of the Experimental Analysis of Behavior, 1962, 5, 167.

KENDALL, S. B. Some effects of fixed-interval duration on response rate in a two-component chain schedule. Journal of the Experimental Analysis of Behavior, 1967, 10, 341.

\title{
Elicitation of stimulus-bound behavior in guinea pigs ${ }^{1}$
}

\begin{abstract}
ANTHONY G. PHILLIPS ${ }^{2}$ and ELLIOTS. VALENSTEIN, Fels Research Institute, Yellow Springs, Ohio 45387
\end{abstract}

The elicitation of stimulus-bound eating, drinking, and gnawing in the guinea pig is described. In contrast to experience with the rat, hypothalamic stimulation elicits eating more frequently than drinking in the guinea pig and the probability of occurrence of stimulus-bound behavior is much higher.

A great number of studies have investigated the consummatory behavior that could be elicited by electrical stimulation of the hypothalamus. This "stimulus-bound" behavior has included, among others, eating, drinking, hoarding, stalking-attack, and sexual behavior (cf. reviews by Valenstein, Cox, \& Kakolewski, 1969). Although the behavior elicited has usually been interpreted as a concomitant of the activation of the neural state underlying such drives as hunger, thirst, and other biological needs, this view has recently been questioned. It has been shown, for example, that animals displaying eating or drinking in response to hypothalamic stimulation differ in significant ways from animals that are known to be hungry or thirsty (Valenstein, Cox, \& Kakolewski, 1968b; Valenstein, Kakolewski, \& Cox, 1968). The hypothesis has been postulated that hypothalamic stimulation does not evoke specific drives, but rather activates the neural substrates of a configuration of responses that are adaptive for a given species. ${ }^{3}$ From this point of view, it becomes important to examine the responses that can be elicited by hypothalamic stimulation in a variety of species. We report here the results of a study of the behavior that was elicited by hypothalamic stimulation in the guinea pig.

\section{SUBJECTS}

The Ss were seven male guinea pigs $(450-500 \mathrm{~g})$ purchased from Hilltop Lab Animals, Inc. (Scottdale, $\mathrm{Pa}$.).

\section{PROCEDURE}

The guinea pigs were implanted with two bipolar electrodes (Valenstein, Hodos, \& Stein, 1961) in the hypothalamus at the left and right of the midline. With the skull leveled in the stereotaxic instrument, the electrodes were inserted $4.0 \mathrm{~mm}$ posterior to bregma, $1.75 \mathrm{~mm}$ lateral and $11.0 \mathrm{~mm}$ below the dorsal surface of the calvarium. The histological information for 10 of the 14 electrode placements is summarized in Fig. 1.

The guinea pigs were tested with the same procedure that has become standardized for the rat in our laboratory (Valenste in, Cox, \& Kakolewski, 1968a). The animals were placed in a Plexiglas chamber containing a water bottle with metal drinking tube, a wooden wedge anchored to the floor, and Purina Lab Chow pellets scattered on the floor. A dish of Purina Guinea Pig Chow was also available. The animals were stimulated for 30-sec periods with a 60-cycle sine wave current, which was gradually raised until the animals clearly responded to the stimulation by moving around the cage in what has been described as a "searching pattern." Following the establishment of an appropriate current level, three standard tests consisting of $2030-\mathrm{sec}$ stimulation periods, each separated by a $60-\sec$ interstimulus period, were administered at each electrode site. An $\mathrm{O}$ scored the occurrence of eating, drinking, and gnawing on the wooden wedge. Eating or drinking were scored only when there was clear evidence that the food or water were ingested. Gnawing consisted of biting off pieces of wood from the wedge.

\section{RESULTS AND DISCUSSION}

The results are summarized in Table 1. Two of the animals (four electrode placements) are excluded as the stimulation only barely aroused the animals and the histological examination revealed that the electrodes had partially penetrated through the ventral surface of the brain. It can be seen from an inspection of the table that the majority of the electrodes elicited eating. Drinking and gnawing were observed in fewer instances. Most animals ate both the rat pellets and the guinea pig chow when 

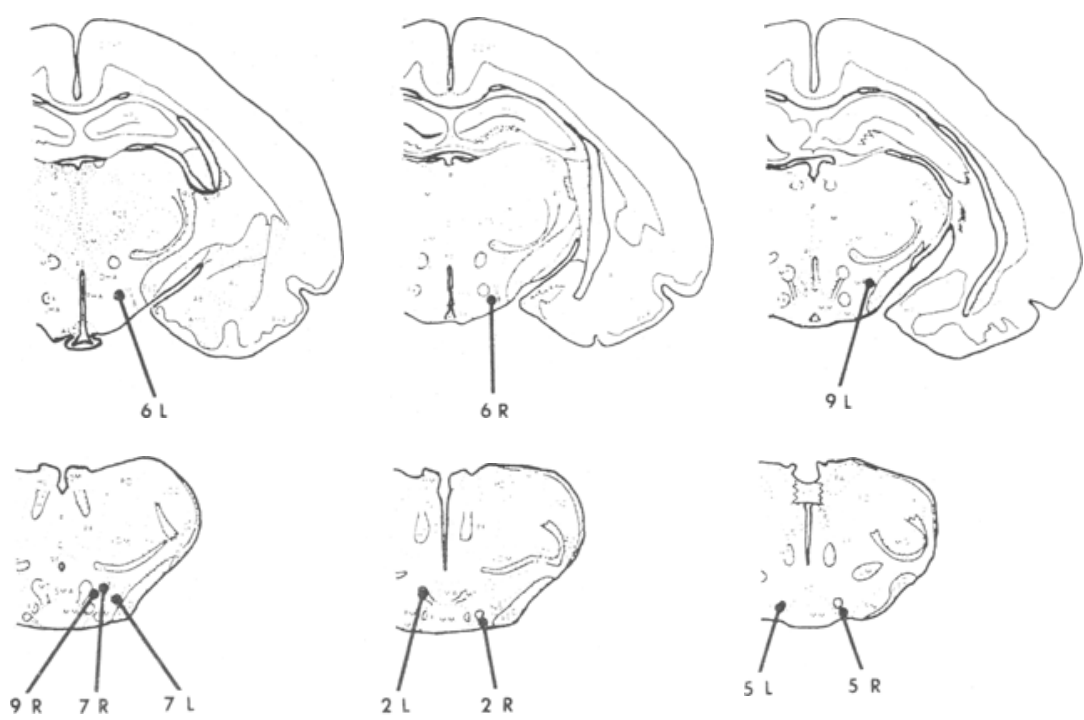

stimulated, but did not eat during the interstimulus periods. Three of the animals $(2 R, 6 R, 7 R)$ preferred the guinea pig chow and they were given an additional standard test with only this food available to determine their consumption. All three animals consumed between 5 and $6 \mathrm{~g}$ of food during the 2030 -sec stimulation periods.

It can be seen that stimulus-bound behavior was elicited by 9 of the 10 electrodes. This percentage of success is much higher than the $35 \%$ success average we have observed in the rats. Typically, stimulated rats are more active than the guinea pigs, and we suspect that some of this activity may constitute a stimulus-bound behavior that substitutes for the

\section{Table 1}

Eating (E), drinking (D), and gnawing (G) behavior elicited by hypothalamic stimulation in the guinea pig. Each test had 20 stimulation periods. Maximum score for any one behavior during a single test is 20 , but the animal could exhibit different behaviors during a single period.

\begin{tabular}{|c|c|c|c|c|c|}
\hline \multirow{2}{*}{$\begin{array}{l}\text { Animal \& } \\
\text { Electrode } \\
\end{array}$} & \multirow[b]{2}{*}{ Behavior } & \multicolumn{3}{|c|}{ Tests } & \multirow{2}{*}{$\begin{array}{c}\text { Stimulus } \\
\text { Intensity }(\mu \mathrm{A}) \\
\end{array}$} \\
\hline & & 1 & 2 & 3 & \\
\hline $2 \mathrm{~L}$ & $\begin{array}{l}\mathbf{E} \\
\mathbf{D} \\
\mathrm{G}\end{array}$ & $\begin{array}{r}18 \\
1 \\
0\end{array}$ & $\begin{array}{r}20 \\
0 \\
0\end{array}$ & $\begin{array}{r}20 \\
2 \\
0\end{array}$ & 12 \\
\hline $2 R$ & $\begin{array}{l}\text { E } \\
\text { D } \\
G\end{array}$ & $\begin{array}{r}17 \\
2 \\
0\end{array}$ & $\begin{array}{l}2 \\
4 \\
0\end{array}$ & $\begin{array}{r}17 \\
7 \\
0\end{array}$ & 30 \\
\hline $5 \mathrm{~L}$ & $\begin{array}{l}\mathbf{E} \\
\mathbf{D} \\
\mathbf{G}\end{array}$ & $\begin{array}{r}13 \\
0 \\
3\end{array}$ & $\begin{array}{l}7 \\
0 \\
1\end{array}$ & $\begin{array}{r}12 \\
0 \\
0\end{array}$ & 20 \\
\hline $5 R$ & $\begin{array}{l}\mathbf{E} \\
\text { D } \\
G\end{array}$ & $\begin{array}{r}17 \\
0 \\
0\end{array}$ & $\begin{array}{l}8 \\
0 \\
3\end{array}$ & $\begin{array}{r}20 \\
0 \\
2\end{array}$ & 60 \\
\hline $6 \mathrm{~L}$ & $\begin{array}{l}\mathbf{E} \\
\mathbf{D} \\
\mathbf{G}\end{array}$ & $\begin{array}{r}20 \\
0 \\
0\end{array}$ & $\begin{array}{r}19 \\
0 \\
3\end{array}$ & $\begin{array}{r}20 \\
1 \\
1\end{array}$ & 22 \\
\hline $6 \mathrm{R}$ & $\begin{array}{l}\mathbf{E} \\
\mathrm{D} \\
\mathrm{G}\end{array}$ & $\begin{array}{r}12 \\
0 \\
0\end{array}$ & $\begin{array}{r}15 \\
0 \\
1\end{array}$ & $\begin{array}{r}20 \\
0 \\
0\end{array}$ & 42 \\
\hline $7 \mathrm{~L}$ & $\begin{array}{l}\text { E } \\
\text { D } \\
G\end{array}$ & $\begin{array}{l}5 \\
1 \\
9\end{array}$ & $\begin{array}{l}3 \\
1 \\
5\end{array}$ & $\begin{array}{l}3 \\
0 \\
9\end{array}$ & 35 \\
\hline $7 \mathrm{R}$ & $\begin{array}{l}\mathbf{E} \\
\mathrm{D} \\
\mathbf{G}\end{array}$ & $\begin{array}{r}17 \\
4 \\
6\end{array}$ & $\begin{array}{l}8 \\
3 \\
9\end{array}$ & $\begin{array}{r}12 \\
2 \\
8\end{array}$ & 16 \\
\hline 9L & $\begin{array}{l}\mathbf{E} \\
\mathbf{D} \\
\mathrm{G}\end{array}$ & $\begin{array}{l}0 \\
0 \\
0\end{array}$ & $\begin{array}{l}0 \\
0 \\
0\end{array}$ & $\begin{array}{l}0 \\
0 \\
0\end{array}$ & 34 \\
\hline $9 R$ & $\begin{array}{l}\mathbf{E} \\
\mathbf{D} \\
\mathbf{G}\end{array}$ & $\begin{array}{r}13 \\
12 \\
2\end{array}$ & $\begin{array}{r}11 \\
7 \\
13\end{array}$ & $\begin{array}{l}9 \\
3 \\
2\end{array}$ & 10 \\
\hline
\end{tabular}

Fig. 1. The location of electrodes in the hypothalamus of the guinea pig (adapted from Tindal, 1965).

consummatory patterns that are normally scored. ${ }^{3}$ Also to be noted is the high incidence of eating over drinking in the guinea pig, whereas in our experience the converse is true in the rat. Guinea Pig 7 exhibited a relatively high incidence of gnawing from both electrodes although the placement was not identical. This tendency for an animal to exhibit the same behavior in response to stimulation at widely disparate electrode sites had previously been observed in the rat. ${ }^{4}$ We do not regard it appropriate to comment extensively on the correlation of anatomical site with elicited behavior until a greater number of cases have been studied in this species, but we would note the fact that posterior electrodes located a long distance from the traditional lateral hypothalamic feeding area were capable of evoking feeding behavior. In addition to its contribution to the problem of species differences, the guinea pig should be considered a valuable animal for studying stimulus-bound behavior because of the high probability of success.

$$
\text { REFERENCES }
$$

TINDAL, J.S. The forebrain of the guinea pig in stereotaxic coordinates. Journal of Comparative Neurology, 1965, 124, 259-266.

VALENSTEIN, E. S., \& COX, V. C. The influence of hunger, thirst and previous experience in the test chamber on stimulus-bound eating and drinking. Journal of Comparative \& Physiological Psychology, in press.

VALENSTEIN, E. S., COX, V. C., \& KAKOLEWSKI, J. $w$. Modification of motivated behavior elicited by electrical stimulation of the hypothalamus. Science, 1968a, 159, 1119-1121.

VALENSTEIN, E. S., $\operatorname{cox}, \quad$ v. $\quad$ C., \& KAKOLEWSKI, J. $w$. The motivation underlying eating elicited by lateral hypothalamic stimulation. Physiology \& Behavior, 1968b, 3, 969-971.

VALENSTEIN, E. S., COX, v. C., \& KAKOLEWSKI, J. W. The hypothalamus and motivated behavior. In J. Tapp (Ed.), Reinforcement. New York: Academic Press, 1969. Pp. 242-285.

VALENSTEIN, E. S., HODOS, W., \& STEIN, L. A simplified electrode assembly for implantation of chronic brain electrodes in small animals. American Journal of Psychology, 1961, 74, 125-128.

VALENSTEIN, E. S., KAKOLEWSKI, J. W., \& COX, V. C. A comparison of stimulus-bound drinking and drinking induced by water deprivation. Communications in Behavioral Biology, 1968, 2, 227-233. NOTES

1. Supported by National Institute of Mental Health Research Grant M-4529, Research Scientist Award MH-4947, and National Aeronautic and Space Administration Research Grant NGL 36-005.

2. On leave from the University of Western Ontario.

3. Valenstein, E. S., Cox, V. C., \& Kakolewski, J. W. A reexamination of the hypothalamus in motivation. Submitted for publication. 